\title{
Relevance of trichothecenes in fungal physiology: Disruption of tri5 in Trichoderma arundinaceum
}

\author{
Mónica G. Malmierca ${ }^{\mathrm{a}}$, Rosa Elena Cardoza ${ }^{\mathrm{a}}$, Nancy J. Alexander ${ }^{\mathrm{b}}$, Susan P. McCormick ${ }^{\mathrm{b}}$, Isidro G. Collado ${ }^{\mathrm{c}}$, \\ Rosa Hermosa ${ }^{\mathrm{d}}$, Enrique Monte ${ }^{\mathrm{d}}$, Santiago Gutiérrez ${ }^{\mathrm{a}, *}$ \\ ${ }^{a}$ Area of Microbiology, University School of Agricultural Engineers, University of León, Campus de Ponferrada, Avda. Astorga s/n, 24400 Ponferrada, Spain \\ ${ }^{\mathrm{b}}$ Bacterial Foodborne Pathogen and Mycology Unit, USDA/ARS, National Center for Agricultural Utilization Research, Peoria, IL 61604-3902, USA \\ ${ }^{\mathrm{c}}$ Department of Organic Chemistry, Faculty of Sciences, University of Cádiz, Torre Sur, 4 Planta, 11510 Puerto Real, Spain \\ ${ }^{\mathrm{d}}$ Spanish-Portuguese Centre of Agricultural Research (CIALE), Department of Microbiology and Genetics, University of Salamanca, C/Río Duero 12, 37185 Salamanca, Spain
}

\section{A R T I C L E I N F O}

\section{Article history:}

Received 16 September 2012

Accepted 8 February 2013

Available online 27 February 2013

\section{Keywords:}

Trichoderma

Trichothecene

Terpene

Ergosterol

Squalene

Biocontrol

\begin{abstract}
A B S T R A C T
Trichothecenes are sesquiterpenoid mycotoxins produced mainly by Fusarium species. Harzianum A (HA), a non-phytotoxic trichothecene produced by Trichoderma arundinaceum, has recently been found to have antagonistic activity against fungal plant pathogens and to induce plant genes involved in defense responses. In the present work, we have shown that disruption of the T. arundinaceum tri5 gene, which encodes a terpene synthase, stops the production of HA, alters the expression of other tri genes involved in HA biosynthesis, and alters the expression of $h m g R$, dpp1, erg9, erg1, and erg7, all genes involved in terpene biosynthetic pathways. An increase in the level of ergosterol biosynthesis was also observed in the tri5 disrupted transformant in comparison with the wild type strain. The loss of HA also resulted in a drastic reduction of the biocontrol activity of the transformants against the phytopathogenic fungi Botrytis cinerea and Rhizoctonia solani. Finally, the effect of tri5 gene disruption on the regulation and balance of intermediates in terpene biosynthetic pathways, as well as the hypothetical physiological role of trichothecenes, both inter- and intracellularly, on regulation and biocontrol, are discussed.
\end{abstract}

(c) 2013 Elsevier Inc. All rights reserved.

\section{Introduction}

Trichoderma is well known for the ability of some of its strains to act as important biocontrol agents against phytopathogenic fungi (Harman et al., 2004; Lorito et al., 2010). In interactions with plants, it has been shown that some Trichoderma strains can act as biofertilizers, as inducers of plant defense responses, and also can increase tolerance to abiotic stresses (Shoresh et al., 2010; Hermosa et al., 2012). Many Trichoderma strains produce primary or secondary metabolites and enzymes with diverse industrial interest. Among the metabolites produced by Trichoderma, trichothecenes have attracted attention in recent years because they are described as important mycotoxins, with phytotoxicity as well as animal and human toxicity (Desjardins, 2006; McCormick et al., 2011). Trichoderma species of the Brevicompactum clade, Trichoderma brevicompactum and Trichoderma arundinaceum, produce two different trichothecenes, trichodermin and Harzianum A (HA), respectively. While trichodermin is known to be phytotoxic, Harzianum A is not. Thus, HA serves as a model of a nonphytotoxic trichothecene produced by a fungal strain that shows

\footnotetext{
* Corresponding author. Fax: +34 987442070.

E-mail address: s.gutierrez@unileon.es (S. Gutiérrez).
}

a significant biocontrol activity (Malmierca et al., 2012), and can be used to study the impact of trichothecenes in fungal physiology.

The genes involved in the biosynthesis of trichothecenes (tri genes) in $T$. brevicompactum and T. arundinaceum have been recently cloned and characterized (Cardoza et al., 2011; Tijerino et al., 2011; Malmierca et al., 2012). It was shown that the tri genes are clustered, similar to that which occurs in Fusarium, but these two genera have important differences in the genetic organization of these genes. The Fusarium tri genes are located at three different loci, with the main locus including 12 genes with tri5 located at a central position. The tri5 gene in both Fusarium and Trichoderma encodes trichodiene synthase, a terpene cyclase that catalyzes the first step of the trichothecene biosynthetic pathway, converting farnesyl diphosphate (FPP) to trichodiene (Hohn and Van Middlesworth, 1986; Hohn and Desjardins, 1992; Cardoza et al., 2011). In contrast, the "main cluster" of tri genes in Trichoderma does not contain the tri5 gene, and includes only seven genes with a marked difference in their relative organization in comparison with that of the tri genes of Fusarium (Cardoza et al., 2011). This is the only trichothecene producer described so far in which tri5 is not located in the main tri cluster. In Trichoderma, trichodiene is oxygenated at the $\mathrm{C} 2, \mathrm{C} 11$, and $\mathrm{C} 12$ positions by the Tri4 protein (trichodiene monooxygenase) giving rise to isotrichodiol, which is non-enzymatically converted to 12,13-epoxytrichothecene (EPT), 
and afterwards oxygenated at $\mathrm{C} 4$ by the Tri11 protein (trichothecene monooxygenase) to produce trichodermol. The latter is finally acylated by the Tri3 protein (trichodermol acyltransferase) that adds a 2,4,6 octatriendioyl side chain to the C-4 hydroxyl group to produce HA (Fig. 3B) in T. arundinaceum or an acetyl to the C-4 hydroxyl group in T. brevicompactum to produce trichodermin (Cardoza et al., 2011; Tijerino et al., 2011). Thus, tri5 and the gene/s hypothetically involved in the biosynthesis of the octatrienedioyl side chain, the latter of which has not yet been cloned, would be in other genomic locations.

Previously we described the characterization of a tri4 gene disrupted transformant (Malmierca et al., 2012). Surprisingly, this transformant showed traces of HA production as well as production of 12,13-epoxytrichoene-2-ol derivatives, the production of which may have been due to one or more non-specific P450 oxygenases. In that tri4 disrupted transformant, an increase in total chitinase activity and a reduction in biocontrol activity were detected. However, it was not determined if these observed results were due to the disruption of the tri4 gene alone or from the production of the additional 12,13-epoxytrichoene-2-ol derivatives.

In the present work, we describe the isolation of a T. arundinaceum mutant carrying a disrupted tri5 gene. This mutant allowed us to characterize the effect of a total lack of trichothecene production on several phenotypic characteristics of Trichoderma, as well as genotypic influences on the level of expression of other genes. Five genes in the terpene biosynthetic pathway were chosen for the study. dpp1 is involved in the dephosphorylation of several isoprenoid phosphates, including FPP conversion to farnesol (Faulkner et al., 1999), a compound that acts as an important regulator of the cellular levels of FPP. hmgR, encodes hydroxymethylglutaryl CoA (HMG-CoA) reductase that catalyzes the production of mevalonate from HMG-CoA. This gene/enzyme is regulated at several levels, including transcription, translation, and enzyme degradation (Goldstein and Brown, 1990; Meigs and Simoni, 1997; Leichner et al., 2011). erg9 encodes squalene synthase, the enzyme that is responsible for the first specific step of ergosterol biosynthesis, converting FPP into squalene. erg9 has been described as a key target in the regulation of ergosterol biosynthesis (Asadollahi et al., 2010). erg1 encodes squalene epoxidase, an enzyme involved in the oxygenation of squalene giving rise to oxidosqualene in a reaction that implies the entry of the squalene in an energy costly branch that produces ergosterol (Leichner et al., 2011). Lastly, erg7 encodes oxidosqualene cyclase, which is involved in the cyclization of oxidosqualene to produce lanosterol (Corey et al., 1994).

Finally, we describe the effect of $T$. arundinaceum tri5 disruption on antifungal activity.

\section{Materials and methods}

2.1. Strains, culture media, and culture conditions used in the present work

T. arundinaceum IBT 40837 (=Ta37) (IBT Culture Collection of Fungi at the Department of Biotechnology, Technical University of Denmark) was kindly provided by Ulf Thrane. For trichothecene analysis and RNA isolation, $T$. arundinaceum strains were grown using a two-step procedure in $\mathrm{CM}(0.5 \%$ malt extract, $0.5 \%$ yeast extract, $0.5 \%$ glucose) followed by growth in PDB modified medium as described previously (Cardoza et al., 2011). For ergosterol and squalene quantification, Ta37 and $\mathrm{Ta} \Delta \mathrm{Tri} 5$ spores were inoculated in CM medium and incubated at $28^{\circ} \mathrm{C}, 250 \mathrm{rpm}$, for $24 \mathrm{~h}$. Then, $4 \mathrm{~g}$ (wet weight) of filtered mycelia were added to $100 \mathrm{ml}$ of PDB modified medium and incubated at $28^{\circ} \mathrm{C}, 250 \mathrm{rpm}$, for 24 and $96 \mathrm{~h}$.

Phytopathogens Botrytis cinerea 98, isolated from diseased strawberry plants, Rhizoctonia solani CECT 2815, Myrothecium roridum ATCC 52485, and Fusarium sporotrichioides CECT 20166 were used as targets in the dual confrontation assays. B. cinerea and $R$. solani were also included in growth assays on membranes.

All fungal strains were routinely maintained on PDA (2.4\% PDB, $2 \%$ agar), except $B$. cinerea and Ta37, which were maintained on MEA ( $2 \%$ glucose, $2 \%$ malt extract, $1 \%$ peptone, $2 \%$ agar, pH 5.6 ) and PPG ( $2 \%$ mashed potatoes, $2 \%$ glucose, $2 \%$ agar), respectively.

Three Solanum lycopersicum varieties: var. Marmande (Semillas Battle S.A., Barcelona, Spain), var. Tres Cantos and var. Muchamiel (Rocalba S.A., Girona, Spain) were used for fungal-plant interaction studies.

\subsection{Construction of $p \Delta$ tri5 and pUStri5 plasmids}

A 784 bp fragment (GenBank accession number FR715494) of the tri5 gene (from 54 to $837 \mathrm{bp}$ ) of Ta37 was amplified using iProof High-Fidelity DNA Polymerase (BioRad, Hercules, CA) and primer pair 2100/2101 (Table S1a, Supplementary data) (the latter primer with an Ascl restriction site at the end) using genomic DNA as template. The amplicon was band-purified with the Ultraclean DNA purification kit (MoBio, Carlsbad, CA) and cloned into $\mathrm{PCR}^{\mathrm{TM}} 4$ Blunt-TOPO ${ }^{\circledR}$ (Invitrogen, Carlsbad, CA). The resulting plasmid was cut with AscI and ligated with a chimeric hygromycin B gene $(2.5 \mathrm{~kb})$ (Turgeon et al., 1987), which contained AscI restriction sites at both ends of the chimera, leading to the final $7.3 \mathrm{~kb} \mathrm{p} \Delta$ tri5 vector (Fig. S1A, Supplementary data).

For construction of the pUStri5 plasmid, intact tri5 was amplified by PCR using Pfu polymerase and the primer pair 2114/2115 (Table S1a, Supplementary data). The $1.2 \mathrm{~Kb}$ DNA fragment was gel purified and cloned into the BamHI restriction site of pAN52.1 (Punt et al., 1987). The resulting plasmid was digested with StuI and HindIII and the $3.8 \mathrm{~Kb}$ band that contained the tri5 expression cassette was gel purified and cloned into the EcoRI restriction site of pUSR0 (Cardoza et al., 2006a), thus obtaining the $17.1 \mathrm{~Kb}$ plasmid pUStri5 with the phleomycin resistance gene as selectable marker (Fig. S2B, Supplementary data).

\subsection{Transformation of $T$. arundinaceum}

The host fungus was transformed with plasmid $\mathrm{p} \Delta$ tri5 using a protoplast transformation protocol as described previously (Malmierca et al., 2012). Transformants were selected by hygromycin B $(100 \mu \mathrm{g} / \mathrm{ml})$ resistance. The selected transformants were analyzed by PCR using the primer pairs $2114 / 2115$ and 2114/T7 (Table S1a, Supplementary data) using the Terra ${ }^{\mathrm{TM}}$ PCR Direct Polymerase Mix (Clontech, Mountain View, CA) and by Southern hybridization to detect those with the $\mathrm{p} \Delta$ tri5 vector inserted into the tri5 gene.

Strain Ta $\Delta$ Tri5 was transformed with pUStri5 plasmid by using Agrobacterium-mediated transformation as described previously (Cardoza et al., 2006a). The transformants were selected by phleomycin $(30 \mu \mathrm{g} / \mathrm{ml})$ resistance, and after two rounds of growth in selective medium, transformants were analyzed by PCR using the primer pair 2114/pAN52-trpC (Table S1a, Supplementary data) and the same procedures as above.

\subsection{Extraction and chemical analysis of $H A$}

Cultures of wild-type and transformants were analyzed by high-performance liquid chromatography (HPLC) for HA as previously described (Cardoza et al., 2011).

\subsection{Antifungal assays}

\subsubsection{Direct confrontation assay}

In vitro confrontation assays between Trichoderma strains (Ta37 and the disruptant strain Ta $\Delta$ Tri5) and the pathogens $R$. solani, 
$M$. roridum, and $F$. sporotrichioides (on PDA plates), and B. cinerea (on MEA plates), were established as described in Malmierca et al. (2012). Assays were performed in triplicate, and single cultures of Trichoderma strains and pathogens were used as control. Photographs were taken after 10 days.

\subsubsection{Growth assay on membranes}

To test the effect of Trichoderma metabolites on the growth of selected fungal plant pathogens, 5-mm-diameter PDA plugs of Ta37 or disrupted strain Ta $\Delta$ Tri5 were placed at the center of Petri dishes containing PDA or MEA medium, on cellophane sheets (Shengzhou Pengyu Trading Co, Ltd., Zhejiang, China) or $10 \mathrm{kDa}-$ cut-off dialysis membranes (Sigma, St. Louis, MO). After 2 days of incubation at $28^{\circ} \mathrm{C}$, the membranes were removed from the plates and a single 5-mm diameter mycelial plug of the pathogen $R$. solani on PDA plates and $B$. cinerea on MEA plates was placed at the center of the dish. In parallel, the pathogens were grown on PDA or MEA (control plates). Each pathogen was tested on three plates. Growth diameters were measured after 72 and $96 \mathrm{~h}$ for $R$. solani and $B$. cinerea, respectively. The results are expressed as percentages of growth inhibition of each pathogen by Trichoderma strains.

To test the permeability of each type of membrane to HA, control and test plates were prepared. Control plates were made by adding $40 \mu \mathrm{l}$ of acetonitrile over MEA plates with either cellophane or dialysis membranes. When the surface of the plate was dry, either no Trichoderma plug was added, or an agar plug of Ta37 or $\mathrm{Ta} \Delta$ Tri 5 was added. After 2 days of incubation at $28^{\circ} \mathrm{C}$, the membranes were removed and a single $5-\mathrm{mm}$ diameter mycelia plug of $B$. cinerea was placed in the center of the dish. Growth diameter was measured after $72 \mathrm{~h}$. For the test HA plates, $30 \mu \mathrm{g}$ of HA (dissolved in acetonitrile, $40 \mu \mathrm{l}$ total volume) was added onto the membrane, allowed to dry, and then a plug of Ta37 or Ta $\Delta$ Tri5 was added. After 2 days of incubation, the membranes were removed and a plug of $B$. cinerea was placed on the center of the plate. Growth was determined as above. Comparisons were calculated between the test plates and the control plates. All plates were done in triplicate.

\subsection{Tomato plant assays}

Surface sterilized tomato seeds were planted in commercial loamy field soil [Kekkilä 50/50 (Projar S.A., Valencia, Spain), refer to Malmierca et al. (2012) for composition]. Pots were incubated in a greenhouse at $22 \pm 4{ }^{\circ} \mathrm{C}$, and watered as needed. Eighteen dayold leaves were cut and placed in Petri dishes with sterile wet filter paper on the bottom. Then, $15 \mu \mathrm{l}$ of $B$. cinerea conidial suspensions $\left(5 \times 10^{5}\right.$ spores $\left./ \mathrm{ml}\right)$ in germination buffer $(20 \mathrm{mM}$ glucose and

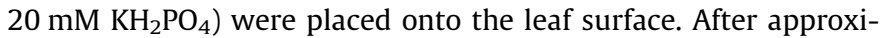
mately $4 \mathrm{~h}$ (when the $B$. cinerea conidial suspension was dry) $15 \mu \mathrm{l}$ of Ta37 or Ta $\Delta$ Tri5 filter sterilized broth (or PDB medium in control assays) were placed over the conidial suspension spot and the dishes were incubated in a greenhouse at $22^{\circ} \mathrm{C}$ for $96 \mathrm{~h}$. Three inoculations were made per leaf on twelve leaves per treatment and three replicates for each experiment. The necrotic lesions were measured every $24 \mathrm{~h}$.

\subsection{Chitinase activity assays}

Cultures of the different strains were grown in modified PDB medium at $28{ }^{\circ} \mathrm{C}, 250 \mathrm{rpm}$, for $96 \mathrm{~h}$. Supernatant samples of $8 \mathrm{ml}$ were taken every $24 \mathrm{~h}$. The extracellular chitinase activity was quantified using $p$-NP- $\beta$-D-glucosaminide ( $p$-NP $\beta D G$ ) (Sigma, St. Louis, MO) as substrate as previously described in Malmierca et al. (2012).

\subsection{Assay of hydroxymethylglutaryl Coenzyme A reductase activity}

HMG-CoA reductase was measured as described by Servouse and Karst (1986) and Cardoza et al. (2007) with slight modifications. The mycelia of all strains were ground with liquid nitrogen in a mortar, the powder was resuspended in $0.1 \mathrm{M}$ sodium phosphate buffer, pH 7.0, containing 0.5\% Triton-X100, 1 mM EDTA, $10 \mathrm{mM}$ dithiothreitol (DTT), and a protease inhibitor cocktail containing: $0.5 \mathrm{mM}$ 4-(2-aminoethyl) benzenesulfonyl fluoride (AEBSF), $2.5 \mathrm{mM}$ 1,10-phenanthroline, $11 \mu \mathrm{M}$ pepstatin $\mathrm{A}$, and $7 \mu \mathrm{M}$ of cysteine protease E-64 (Sigma, St. Louis, MO). The homogenate was incubated for $90 \mathrm{~min}$ at $0{ }^{\circ} \mathrm{C}$, centrifuged at $1000 \mathrm{~g}$ for $5 \mathrm{~min}$, and the resulting supernatant was centrifuged again at $8000 \mathrm{~g}$ for $15 \mathrm{~min}$.

The reaction mixture contained, in $0.5 \mathrm{ml}$ of assay buffer (assay buffer was the homogenization buffer without protease inhibitors), $150 \mu \mathrm{M}$ NADPH and $100 \mu \mathrm{l}$ of the supernatant. Endogenous oxidation of NADPH was recorded at $340 \mathrm{~nm}$, with a Varian Cary 50 spectrophotometer before starting the reaction with $100 \mu \mathrm{M}$ of HMG-CoA. The reaction was incubated at $30^{\circ} \mathrm{C}$ and the specific activity was calculated as nmol of NADPH oxidized per min per mg of protein.

Protein concentration was determined by the Bradford method using ovalbumin as standard (Bradford, 1976).

\subsection{Fragment cloning of T. arundinaceum dpp1, hmgR, erg1, erg7, and erg9 genes}

One orthologue to $d p p 1$, encoding diacylglycerol pyrophosphate phosphatase, was found on each of the available Trichoderma genomes of Trichoderma reesei QM6a, Trichoderma atroviride IMI206040, and Trichoderma virens Gv29-8. Oligonucleotides designed from conserved regions of the $d p p 1$ genes from these fungi (Table S1b, Supplementary data), were used to clone an internal fragment of the T. arundinaceum orthologue gene. The resulting sequence, of $364 \mathrm{bp}$, contains two introns of 71 and $88 \mathrm{bp}$ and encodes for a region of 68 amino acids of the DPP1 protein. This region showed a $91.0,88.2,86.8$, and $35.7 \%$ similarity with the T. reesei, T. atroviride, T. virens, and S. cerevisieae DPP1 proteins, respectively.

Fragments of $T$. arundinaceum $\mathrm{hmgR}$, erg1, and erg7 genes, encoding the HMG-CoA reductase (HMGR), squalene epoxidase (ERG1), and oxidosqualene cyclase (ERG7) respectively, were cloned by PCR using degenerate oligonucleotides based on the available sequences of these genes from Trichoderma harzianum (Cardoza et al., 2006b, 2007) (Table S1b). As a result, a 675 bp fragment of the Ta37 hmgR gene was cloned. This fragment, without introns, encodes a region of 225 amino acids of the HMGR protein, showing an 81.5, 80.7, 77.0, and 75.3\% similarity with the T. harzianum, $T$. virens, $T$. atroviride, and $T$. reesei HMGR proteins respectively. Secondly, a 408 bp fragment without introns, corresponding to the Ta37 erg1 gene was cloned and encodes for a region of 136 amino acids of the ERG1 protein which showed similarities of 95.6, 94.9, 92.6, and $89.0 \%$, when compared with its orthologues in T. harzianum, $T$. reesei, $T$. virens, and $T$. atroviride respectively. In parallel, a 618 bp fragment, internal to the Ta37 erg7 gene, was cloned and sequenced. The 206 amino acids of the ERG7 protein encoded by this region showed a similarity of $90.8 \%$ with the protein of $T$. atroviride and of $87.9 \%$ with its orthologues in T. harzianum, T. reesei, and T. virens.

Finally, one orthologue to erg9, encoding the squalene synthase, was found on the three Trichoderma genomes available. Oligonucleotides based on the conserved regions of the erg9 genes from these fungi (Table S1b), were designed and used to clone an internal fragment of the T. arundinaceum orthologue gene. The resulting fragment, of $590 \mathrm{bp}$ without introns, encodes a region of 196 
amino acids that showed an $89.8,87.8$, and $86.2 \%$ similarity with the ERG9 proteins from $T$. reesei, $T$. virens and, $T$. atroviride respectively.

These internal fragment sequences, once they were confirmed to correspond to the predicted genes, were used to design oligonucleotides (Table S1c, Supplementary data) to study the relative level of expression of their corresponding genes in the Ta $\Delta \operatorname{Tri} 5$ mutant in comparison with the wild type Ta37 strain, by qPCR.

\subsection{Ergosterol and squalene quantification}

Total intracellular sterols were extracted and ergosterol and squalene content were calculated as reported previously by Cardoza et al. (2007) and Ghimire et al. (2009), respectively. All measurements were made in triplicate.

\subsection{Inhibition of Botrytis spore germination assay}

To determine if culture broths of the different Trichoderma strains affect the germination of spores of $B$. cinerea, we tested several volumes (ranging from 5 to $25 \mu \mathrm{l}$ ) of filter sterilized supernatants from Ta37 or Ta $\Delta$ Tri5 culture in a microtiter plate. Each well was filled with the desired volume of the Trichoderma broths, $5 \mu \mathrm{l}$ of $B$. cinerea spores (containing 300 spores) in germination buffer, and PDB medium up to a final volume of $100 \mu$. The microtiter plate was covered by a film to maintain high humidity and incubated in darkness at $22{ }^{\circ} \mathrm{C}$ overnight. Spores/germlings were observed under $4 \times$ magnification. Each combination was performed in triplicate and three independent experiments were made.

\subsection{Nucleic acids extraction and manipulation}

The procedures for fungal genomic DNA isolation and for Southern hybridization were performed as described previously (Cardoza et al., 2011).

To isolate total RNA, Trichoderma strains were grown as indicated above. Then, mycelia were recovered from PDB modified medium by filtration, washed with $0.9 \% \mathrm{NaCl}$, dried on absorbent filter paper, frozen with liquid nitrogen, and ground in a mortar. RNA was extracted with the phenol-SDS method (Ausubel et al., 1987 ) and treated with RNase protector and DNase (Fermentas, Vilnius, Lithuania).

The cDNA was synthesized using one $\mu \mathrm{g}$ of total RNA and a Reverse Transcription System using an Oligo(dT) ${ }_{15}$ primer (Promega, Madison, WI).

Labelling, hybridization, and immunological detection were carried out with a nonradioactive labelling and immunological detection kit with CDP-Star as the chemiluminescent substrate (Roche, Mannheim, Germany), as previously described (Cardoza et al., 2007).

\subsection{3. $q P C R$ experiments}

In order to perform comparative studies of the T. arundinaceum gene expression levels, oligonucleotides were designed based on the sequences of the studied genes (Table S1c, Supplementary data). In T. arundinaceum, according to the GeNorm software (Vandesompele et al., 2002) results, $\alpha$-actin and gpd were used as reference genes. For the sequence of oligonucleotides used in the qPCR analysis of T. arundinaceum tri and housekeeping genes, see Malmierca et al. (2012). The qPCR reactions were carried out using Step One Plus ${ }^{\mathrm{TM}}$ (Applied Biosystems, USA). The reactions were performed in a total volume of $20 \mu \mathrm{l}: 10 \mu \mathrm{l}$ Power SYBR ${ }^{\circledR}$ Green PCR Master Mix (Applied Biosystems, USA), $0.4 \mu$ l Forward Primer $10 \mu \mathrm{M}, 0.4 \mu \mathrm{l}$ Reverse Primer $10 \mu \mathrm{M}, 5 \mu \mathrm{l}$ cDNA, and $\mathrm{H}_{2} \mathrm{O}$ to $20 \mu \mathrm{l}$. The REST 2009@ software (Pfaffl et al., 2002) was used to calculate the relative expression values and the significance of the differences between the gene expression levels. For each primer pair used in this work, we performed a standard curve with 320 , $160,80,40,20$, and $10 \mathrm{ng}$ cDNA to determine the PCR amplification efficiency (E value). Each measurement was made in triplicate.

\subsection{Statistical analysis}

ANOVA and Mann-Whitney $U$ tests were performed with IBM SSPS Statistics 19 Software.

\subsection{Nucleotide sequence accession numbers}

Sequences of Ta37 obtained in the present work have been deposited in the GenBank database. Accession numbers are as follows: HE866933 for dpp1, HE965020 for hmgR, HE965019 for erg1, HE974352 for erg7, and HF548663 for erg9.

\section{Results}

\subsection{Disruption of tri5 affects phenotype and blocks production of HA}

Plasmid p $\Delta$ tri5 (Fig. S1A, Supplementary data) was transformed into Ta37 to obtain a tri5-disrupted strain. Up to 200 hygromycin Bresistant transformants were analyzed by PCR using oligonucleotide pair 2114/2115 (Table S1a), which amplified a 1.2-kb fragment in a nondisrupted transformant and an $8.5-\mathrm{kb}$ fragment in a Ta $\Delta$ Tri5 disruptant, and with primer pair 2114/T7 (Table S1a) that amplifies a $0.9 \mathrm{~kb}$ band only in the tri5-disrupted mutant. Only transformant \#182 displayed the expected result (Fig. 1).

This Ta $\Delta$ Tri5 transformant displayed significant differences in its phenotypic characteristics, in comparison with its wild type counterpart, as it showed a faster mycelial growth rate when it was grown on solid MMT or PDA media. However, similar growth rates were observed when both strains were grown on PPG medium (Table 1). Additionally, on PPG medium, the tri5-disrupted transformant showed a significant delay in the onset of sporulation in comparison with the wild type strain (Fig. 2).

No HA was detected in the Ta $\Delta$ Tri5 strain culture medium (Fig. 3A), whereas the wild-type strain showed a maximum specific production of $18.6 \mu \mathrm{g} \mathrm{HA} / \mathrm{ml}$ supernatant/mg dry weight at $24 \mathrm{~h}$ of culture (Fig. 3C).

\subsection{Complementation of tri5 gene mutation restores the HA production phenotype}

Strain Ta $\Delta$ Tri5 was transformed with plasmid pUStri5 which contains a cassette of phleomycin resistance as a marker (the Ta $\Delta$ Tri5 mutant is resistant to hygromycin). As a result, 52 phleomycin/hygromycin resistant transformants were isolated. Transformants \#1 to \#25 were analyzed by PCR and 24 of them gave the expected amplification band $(2.0 \mathrm{~kb})$. Ten transformants (\#15 to \#24) were studied to determine their ability to produce HA in $24 \mathrm{~h}$ PDB grown cultures. Of these, three transformants produced detectable levels of HA. Transformants \#17 and \#18 produced low levels of HA $(0.128$ and $0.084 \mu \mathrm{g} \mathrm{HA} / \mathrm{ml}$ supernatant $/ \mathrm{mg}$ dry weight respectively) while transformant \#15 produced $13.96 \mu \mathrm{g}$ $\mathrm{HA} / \mathrm{ml}$ supernatant/mg dry weight. Genomic DNAs from these strains, including transformant \#16 as an HA non-producing control, were isolated and digested with the restriction endonuclease PvuII. The digested DNAs were then hybridized with a $1.2 \mathrm{~kb}$ probe (see Fig. S2A). All the transformants gave the expected bands of 1.3 and $1.5 \mathrm{~kb}$, belonging to the complementation cassette, and an additional band of 1.1 that corresponded to the $3^{\prime}$ region of the endogenous tri5 gene (See Fig. S2A and C). The $1.3 \mathrm{~kb}$ band of the 
(A)

(A1) Ta37

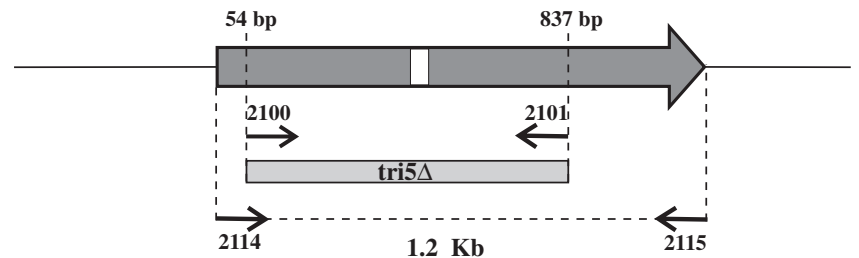

(A2) $\mathrm{Ta} \Delta \mathrm{Tri} 5$

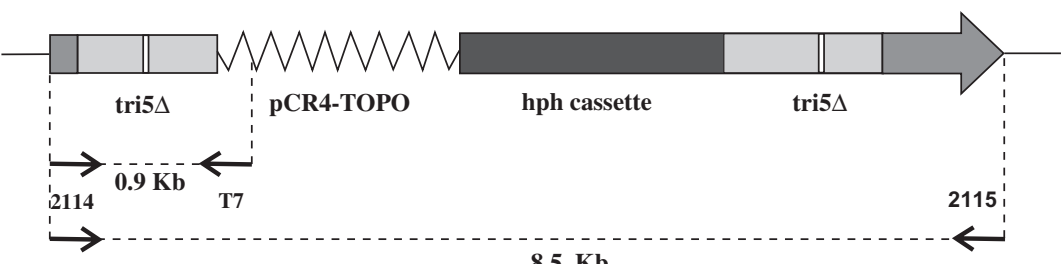

$8.5 \mathrm{~Kb}$

(B)

(B1) $2114 / 2115$

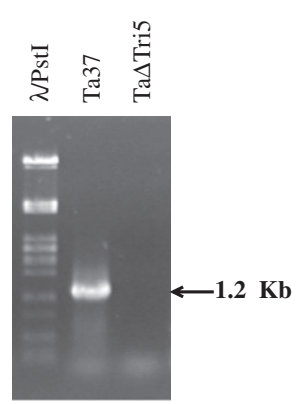

(B2) $2114 / \mathrm{T} 7$

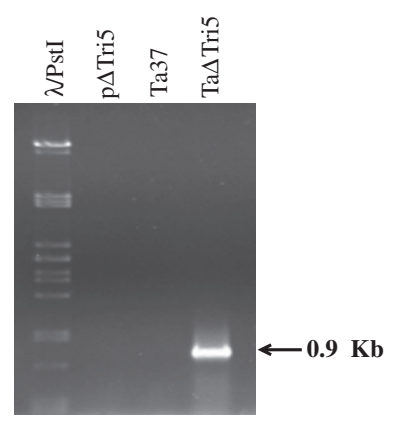

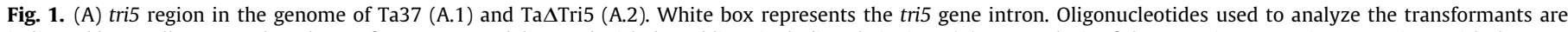

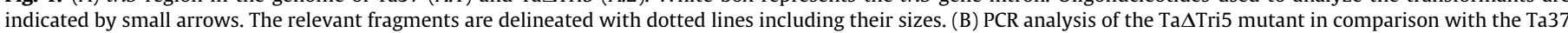

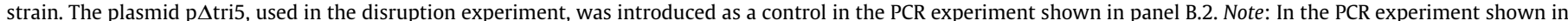

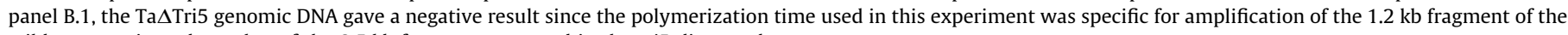
wild type strain and not that of the $8.5 \mathrm{~kb}$ fragment expected in the tri5-disrupted mutant.

Table 1

Growth of Ta37 and Ta $\Delta$ Tri5 strains in three different culture media.

\begin{tabular}{|c|c|c|c|c|c|c|}
\hline & \multicolumn{2}{|l|}{ PPG } & \multicolumn{2}{|l|}{ PDA } & \multicolumn{2}{|l|}{ MMT } \\
\hline & Ta37 & $\mathrm{Ta} \Delta \operatorname{Tri} 5$ & Тa37 & $\mathrm{Ta} \Delta \mathrm{Tri} 5$ & Ta37 & $\mathrm{Ta} \Delta \mathrm{Tri} 5$ \\
\hline $48 \mathrm{~h}$ & $3.50^{\mathrm{a}} \pm 0.20$ & $3.50^{\mathrm{a}} \pm 0.10$ & $2.70^{\mathrm{a}} \pm 0.00$ & $3.00^{\mathrm{b}} \pm 0.10$ & $0.57^{\mathrm{a}} \pm 0.03$ & $2.37^{b} \pm 0.06$ \\
\hline $72 \mathrm{~h}$ & $7.13^{a} \pm 0.30$ & $7.30^{\mathrm{a}} \pm 0.10$ & $4.73^{a} \pm 0.06$ & $5.53^{\mathrm{b}} \pm 0.06$ & $1.13^{a} \pm 0.15$ & $5.43^{b} \pm 0.06$ \\
\hline $96 \mathrm{~h}$ & $8.50^{a} \pm 0.00$ & $8.50^{\mathrm{a}} \pm 0.00$ & $6.90^{\mathrm{a}} \pm 0.10$ & $8.27^{b} \pm 0.06$ & $2.20^{\mathrm{a}} \pm 0.10$ & $8.40^{\mathrm{b}} \pm 0.10$ \\
\hline $120 \mathrm{~h}$ & $8.50^{\mathrm{a}} \pm 0.00$ & $8.50^{\mathrm{a}} \pm 0.00$ & $8.27^{a} \pm 0.06$ & $8.50^{\mathrm{b}} \pm 0.00$ & $3.37^{a} \pm 0.15$ & $8.50^{\mathrm{b}} \pm 0.00$ \\
\hline
\end{tabular}

The numbers indicate the diameter, in $\mathrm{cm}$, of the colonies.

$n=3$, Mann-Whitney U test.

${ }^{\mathrm{a}, \mathrm{b}}$ For each culture medium and time point values followed by different superscript letters are significantly different $(p<0.001)$.

tri5 endogenous copy could not be distinguished in the transformants because it was the same size as the $1.3 \mathrm{~kb}$ band of the complementation cassette.

\subsection{Interruption of tri5 gene affects the expression of other tri genes}

All tri genes, except tri4, are expressed at a higher level in the $\mathrm{Ta} \Delta \mathrm{Tri} 5$ transformant in comparison with the wild type strain
(Fig. 4). tri11 and tri3, which encode the trichothecene C4-monooxygenase and trichodermol C4-acyltransferase respectively, the two structural biosynthetic enzymes following Tri4 in the HA biosynthetic pathway, showed a higher ratio of expression [3.37 $(p=0.000)$ and 4.825 ( $p=0.026)$ fold, respectively] (Fig. 4). In this study, it was possible to determine the effect of the tri5 gene disruption on its own expression, since the construction used to disrupt this gene did not affect the promoter region or the $5^{\prime}$ end of 
Ta37
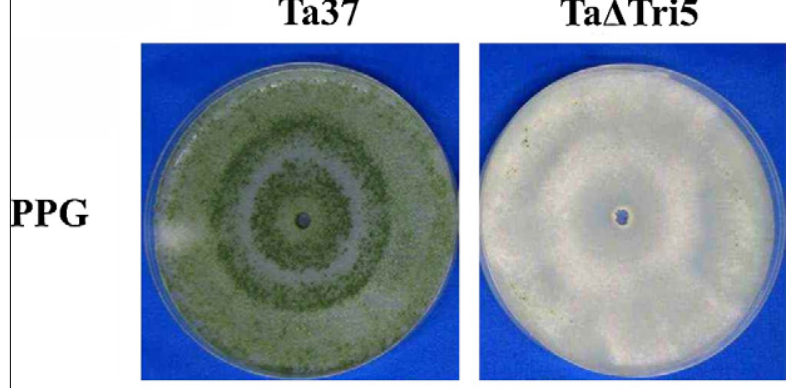

PDA
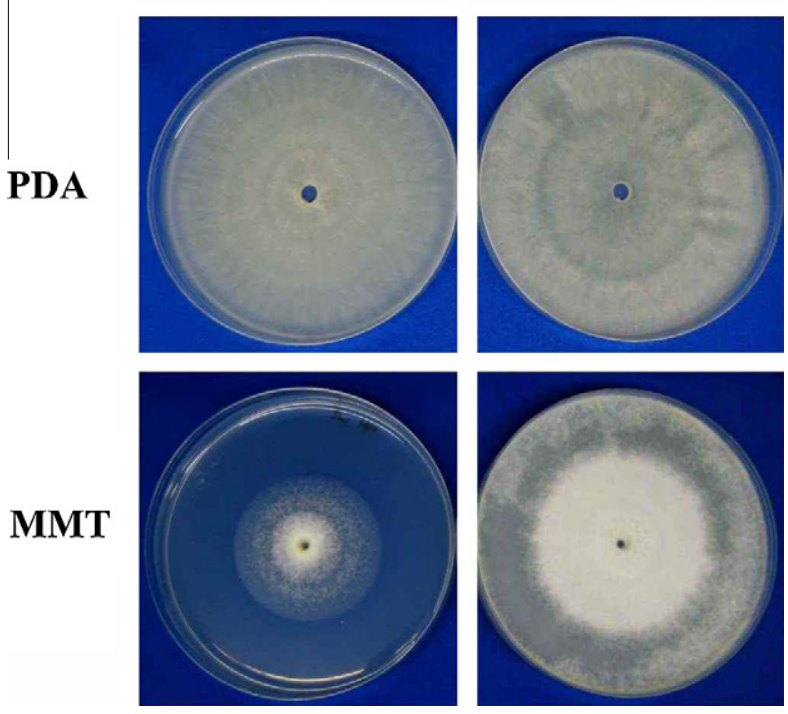

Fig. 2. Growth of Ta37 (wild type) and Ta $\Delta$ Tri5 strains on PPG, PDA, and MMT after 6 days of incubation at $28^{\circ} \mathrm{C}$. On PPG, spores of Ta37 strain are visualized in black bands.

the tri5 gene (where the qPCR primers were located). As a result, the expression of the tri5 gene was slightly induced by a factor of $1.581(p=0.000)$ in the Ta $\Delta$ Tri5 mutant when compared with the Ta37 strain.

\subsection{Expression of $h m g R, d p p 1$, erg9, erg1, and erg7 genes}

The effect of the tri5 gene disruption on the expression of other key genes belonging to the terpene pathway was analyzed. qPCR determined the relative expression of $h m g R, d p p 1, \operatorname{erg} 9$, $\operatorname{erg} 1$, and erg7 between the Ta $\Delta$ Tri5 mutant and the wild type Ta37 strain. When $24 \mathrm{~h}$ grown mycelia were analyzed, an up-regulation of $h m g R, d p p 1$, and $\operatorname{erg} 9$ genes by factors of $3.927(p=0.031), 3.877$ $(p=0.039)$, and 2.503 fold $(p=0.031)$, respectively, was observed.

However, when the comparative level of expression of these genes was determined from mycelia grown for $96 \mathrm{~h}$, it was detected that the expression of $h m g R, \operatorname{erg} 9, \operatorname{erg} 1$, and $\operatorname{erg} 7$ genes was down-regulated by factors of $0.296(p=0), 0.505(p=0.038)$, $0.301(p=0)$, and $0.156(p=0.034)$ respectively, while the expression of dpp1 was not significantly affected (Fig. 5).

\section{5. tri5 Gene interruption increases the hydroxymethylglutaryl-CoA reductase (HMGR) activity}

In order to determine if the tri5 gene disruption affected the general balance of the terpene biosynthetic pathway (see Fig. 8), HMGR activity was quantified. This enzyme catalyzes the synthesis of mevalonate from HMG-CoA and is strongly regulated at various levels. We would expect HMGR activity to vary if the lack of processing of FPP (the precursor of ergosterol and HA) toward HA in the Ta $\Delta$ Tri5 mutant caused the accumulation of sterols and/or other terpenoid compounds. The Ta $\Delta$ Tri5 transformant showed an increase in the level of HMGR activity of $92.4 \%$ and $23.9 \%$ in comparison with the transformed control strain (without insert) at 24 and 96 h of culture respectively (Table 2).

\subsection{Production of ergosterol and squalene}

The Ta $\Delta$ Tri5 transformant showed significantly higher levels of ergosterol production when compared with the Ta37 strain in liquid PDB cultures grown for 24 and $96 \mathrm{~h}$, with the highest difference observed in $24 \mathrm{~h}$ samples $(+85.44 \%) \quad(p<0.05)$. The production of squalene by the Ta $\Delta$ Tri5 mutant was also higher than the wild type strain in samples from $24 \mathrm{~h}$ cultures $(+88.5 \%)$ $(p<0.05)$ but the levels of this triterpene intermediate were not statistically different between the tri5 mutant and the wild type strain in samples from $96 \mathrm{~h}$ cultures (Table 3).

\subsection{Effect of the tri5 gene disruption on the chitinase activity}

The level of chitinase activity, involved in the mycoparasitic activity of Trichoderma, in the tri5-disrupted strain was lower (statistically significant) at 48 and $72 \mathrm{~h}$ of growth when compared to such activity in the control strain (Table 4). These results are in contrast with the significantly higher levels of chitinase activity observed in the tri4-disrupted strain (Malmierca et al., 2012).

\subsection{The tri5 disrupted transformant shows a reduction in antifungal activity against fungal pathogens}

\subsubsection{Growth on membranes}

A membrane assay was used to measure the effect of Trichoderma metabolites, including HA, on the growth of selected fungal plant pathogens. Wild type T. arundinaceum had significant antifungal activity against B. cinerea and $R$. solani (Fig. 6 ) whereas the $\mathrm{Ta} \Delta$ Tri5 transformant had a significant reduction in this antifungal activity, suggesting that HA plays an important role in the mycoparasitic activity of $T$. arundinaceum.

To examine the effect of large versus small molecular weight metabolites, cellophane membranes (allowing small and large metabolites to pass through) were compared with dialysis membranes having a MW cutoff of $10 \mathrm{KDa}$ (allowing only metabolites $<10 \mathrm{KDa}$ to pass through). The reduction of the antifungal activity in the Ta $\Delta$ Tri5 strain against the two phytopathogenic fungi was greater when using dialysis membranes (cutoff, $10 \mathrm{kDa}$ ) than with cellophane (Table 5a). On the dialysis membranes, the reduction in the biocontrol activity, as measured by growth inhibition activity $(\mathrm{RI}=$ radial inhibition $)$, in the $\mathrm{Ta} \Delta \mathrm{Tri} 5$ transformant against $B$. cinerea was $42.4 \%$ [88.8\% (\% seen with Ta37/dialysis) - 46.4\% (\% seen with $\mathrm{Ta} \Delta$ Tri5/dialysis)] and $32.3 \%$ against $R$. solani. In the assays using cellophane membranes, the observed reduction of pathogen growth was lower than that obtained with dialysis membranes, suggesting that since $\mathrm{HA}$ has a MW of $0.4 \mathrm{kDa}$, a metabolite larger than $10 \mathrm{kDa}$ also contributes to the $B$. cinerea and $R$. solani growth inhibition.

To check the permeability of the two different types of membranes to HA, $30 \mu \mathrm{g}$ HA (dissolved in acetonitrile) in a $40 \mu$ l total volume were spread on each membrane, the membrane was lifted off after 2 days, and an agar plug of $B$. cinerea was inoculated. Results are shown in Table 5b, in which it can be observed that HA does permeate both membranes. Exogenous HA inhibits growth of $B$. cinerea by 51.74 or $59.61 \%$ in cellophane or dialysis assays respectively (when comparing control plates with and without exogenous HA). Approximately the same percentage (52.15\%) was obtained in $\mathrm{Ta} \Delta \mathrm{Tri} 5$ cellophane plates while in dialysis plates the value (73.64\%) was higher. Finally, in assays using the Ta37 strain, no significant differences were detected when exogenous 
(A)

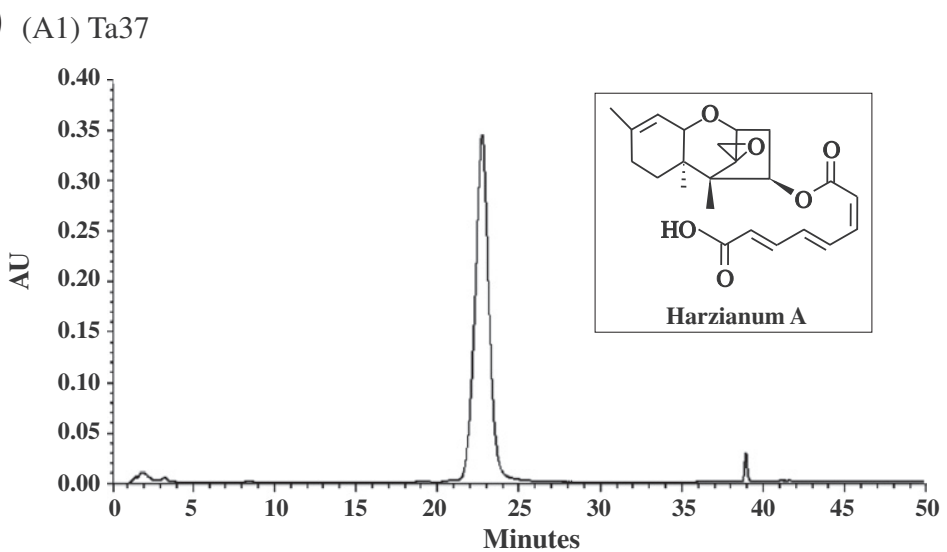

(A2) $\mathrm{Ta} \Delta$ Tri5

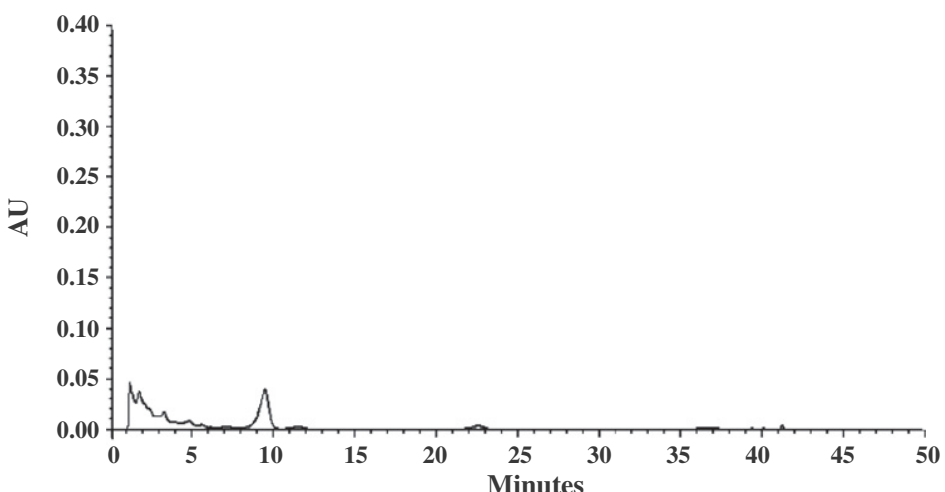

(A3) $\Delta$ Tri5-tri5\#15

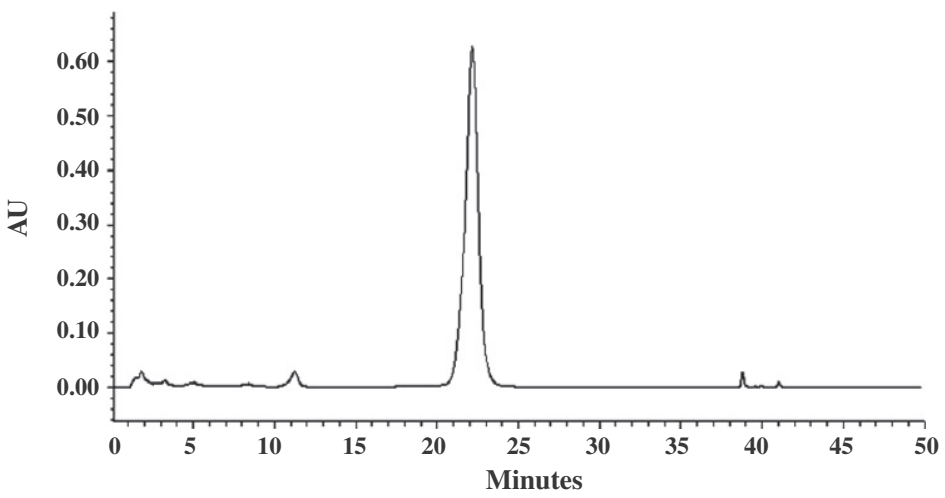

(B)

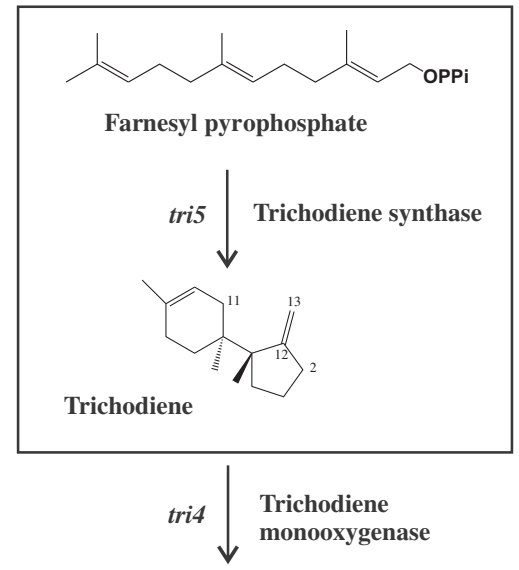

Isotrichodiol

$$
\downarrow \text { Non-enzymatic }
$$

12,13-epoxytrichothec-9-ene (EPT) (trichothecene)

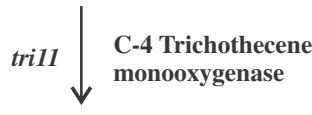

Trichodermol

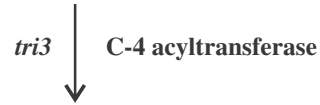

Harzianum A

(C)

\begin{tabular}{c|c|c}
\hline & Ta37 & Ta $\Delta$ Tri5 \\
\hline $\mathbf{2 4} \mathbf{~ h}$ & $18.60 \pm 0.35$ & n.d. \\
$\mathbf{4 8 ~ h}$ & $18.27 \pm 0.50$ & n.d. \\
$\mathbf{7 2 ~ h}$ & $14.75 \pm 0.67$ & n.d. \\
$\mathbf{9 6} \mathbf{~ h}$ & $10.38 \pm 0.78$ & n.d. \\
\hline
\end{tabular}

Fig. 3. (A) HPLC chromatograms of extracts from Ta37 (wild type), Ta $\Delta$ Tri5 (disruptant) and $\Delta$ Tri5-tri5\#15 (add-back) strains, (B) schematic representation of the HA biosynthetic pathway in which the reaction catalyzed by Tri5 protein has been boxed and (C) specific HA production in PDB medium ( $\mu \mathrm{g}$ HA/ml supernatant/mg dry weight) by the T. arundinaceum strains used in the present work

HA was added, because the HA produced by Ta37 is much higher than that exogenously added, thus no effect on the total RI can be seen (Fig. S3, Supplementary data).

\subsubsection{Direct confrontation assays}

Plate confrontation experiments between Ta37 or Ta $\Delta$ Tri5 and the pathogens $B$. cinerea, $R$. solani, $M$. roridum, and F. sporotrichioides were carried out at $28^{\circ} \mathrm{C}$ and plates were photographed after 10 days of incubation (Fig. S4, Supplementary data). In all cases, the four pathogens completely covered the surface after this incubation time on control plates of PDA or MEA. In the confrontation plates, Trichoderma strains overgrew the colonies of $B$. cinerea, $R$. solani, and $F$. sporotrichioides, and surrounded the colonies of M. roridum. Both Trichoderma strains (wild type Ta37 and Ta $\Delta$ Tri5 mutant) were able to inhibit the growth of the four pathogens tested reducing the colony diameter of $B$. cinerea and $M$. roridum to no more than $25 \mathrm{~mm}$. However, Ta $\Delta$ Tri5 was significantly less efficient than Ta37 in the confrontation assays against $B$. cinerea.

\subsubsection{Effect of the culture broths from Ta37 and TaATri5 on B. cinerea} spore germination

Ta37 culture broths inhibit $B$. cinerea spore germination more efficiently than the culture broths from the Ta $\Delta$ Tri5 mutant (Fig. S5, Supplementary data), suggesting that HA is responsible for that inhibition since the only deduced difference between the tri5-disrupted transformant and the Ta37 strain is the production of this trichothecene. 
Ta $\Delta$ Tri5 vs. Ta37

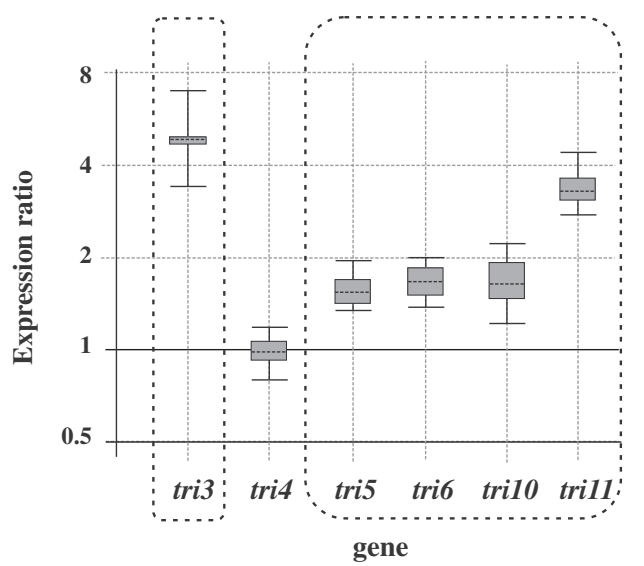

\begin{tabular}{|l|cc|cc|cc|cc|cc|cc|}
\hline & tri3 & $\mathrm{p}\left(\mathrm{H}_{1}\right)$ & tri4 & $\mathrm{p}\left(\mathrm{H}_{1}\right)$ & tri5 & $\mathrm{p}\left(\mathrm{H}_{1}\right)$ & tri6 & $\mathrm{p}\left(\mathrm{H}_{1}\right)$ & tri10 & $\mathrm{p}\left(\mathrm{H}_{1}\right)$ & tri11 & $\mathrm{p}\left(\mathrm{H}_{1}\right)$ \\
\hline TaATri5 vs. Ta37 & $4.825 *$ & $\mathbf{0 . 0 2 6}$ & $\mathbf{0 . 9 8 8}$ & $\mathbf{0 . 9 1 6}$ & $\mathbf{1 . 5 8 1 *}$ & $\mathbf{0 . 0 0 0}$ & $\mathbf{1 . 6 7 6 *}$ & $\mathbf{0 . 0 0 0}$ & $\mathbf{1 . 6 8 3} *$ & $\mathbf{0 . 0 4 1}$ & $\mathbf{3 . 3 7 0 *}$ & $\mathbf{0 . 0 0 0}$ \\
\hline
\end{tabular}

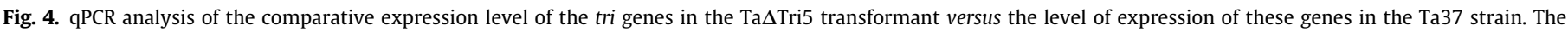

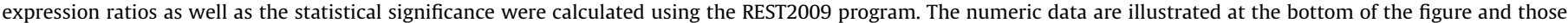
statistically significant $(p<0.05)$ are indicated with an asterisk and are boxed in the graphic representation.

24h. Ta $\Delta$ Tri5 vs. Ta37

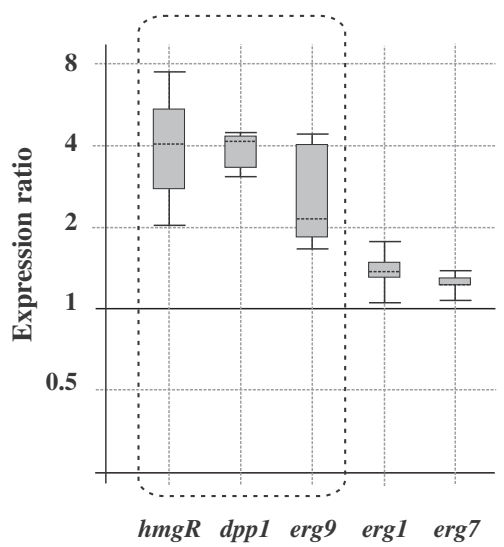

96h. Ta $\Delta$ Tri5 vs. Ta37

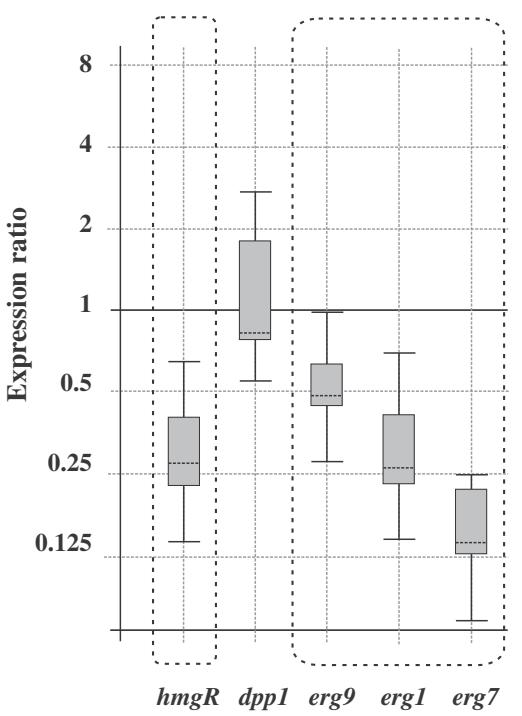

\begin{tabular}{|l|ll|lll|ll|ll|ll|}
\hline & $\operatorname{hmgR}$ & $\mathrm{p}\left(\mathrm{H}_{1}\right)$ & $d p p 1$ & $\mathbf{p}\left(\mathrm{H}_{1}\right)$ & $\operatorname{erg} 9$ & $\mathrm{p}\left(\mathrm{H}_{1}\right)$ & $\operatorname{erg} 1$ & $\mathrm{p}\left(\mathrm{H}_{1}\right)$ & $\operatorname{erg} 7$ & $\mathrm{p}\left(\mathrm{H}_{1}\right)$ \\
\hline 24h. Ta$\Delta$ Tri5 vs. Ta37 & $3.927^{*}$ & $\mathbf{0 . 0 3 1}$ & $3.877^{*}$ & $\mathbf{0 . 0 3 9}$ & $2.503^{*}$ & $\mathbf{0 . 0 3 1}$ & 1.376 & $\mathbf{0 . 0 5 8}$ & $\mathbf{1 . 2 3 7}$ & $\mathbf{0 . 0 5 0}$ \\
\hline 96h. Ta$\Delta$ Tri5 vs. Ta37 & $\mathbf{0 . 2 9 6}$ & $\mathbf{0 . 0 0 0}$ & $\mathbf{1 . 0 7 4}$ & $\mathbf{0 . 8 5 4}$ & $\mathbf{0 . 5 0 5}$ & $\mathbf{0 . 0 3 8}$ & $\mathbf{0 . 3 0 1}$ & $\mathbf{0 . 0 0 0}$ & $\mathbf{0 . 1 5 6 *}$ & $\mathbf{0 . 0 3 4}$ \\
\hline
\end{tabular}

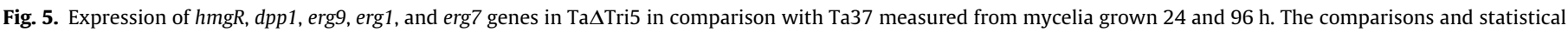

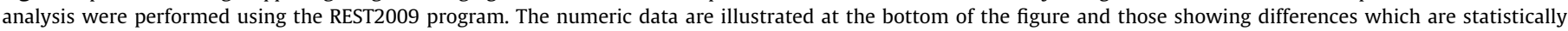
significant $(p<0.05)$ are indicated with an asterisk and are boxed in the graphic representation.

3.8.4. In vitro assay of tomato leaf lesions caused by B. cinerea in the presence of $T$. arundinaceum broth

When Ta37 broth was applied to leaves together with the pathogen inoculum, the production of $B$. cinerea lesions was totally abolished in the tomato varieties Tres Cantos and Muchamiel, while in the variety Marmande only partial inhibition was observed. The use of Ta $\Delta$ Tri5 broth gave rise to lesions in all three tomato varieties tested, although they were significantly smaller $(p<0.05)$ than in the leaves treated only with $B$. cinerea conidia
(Fig. 7 and Table 6), indicating that the broth of the Ta $\Delta$ Tri5 mutant reduced the size of the lesion but failed to prevent lesion formation by $B$. cinerea.

\section{Discussion}

The disruption of the tri5 gene in $T$. arundinaceum resulted in the total absence of the trichothecene HA without production of 
Table 2

Specific HMG-CoA reductase activity (nmol/mg prot) of Ta37-p* and Ta $\Delta$ Tri5 strains.

\begin{tabular}{lllll}
\hline & $24 \mathrm{~h}$ & \% variation & $96 \mathrm{~h}$ & \% variation \\
\hline Ta37-p & $26.9^{\mathrm{a}} \pm 9.13$ & - & $33.8^{\mathrm{a}} \pm 2.29$ & - \\
$\mathrm{Ta} \Delta$ Tri5 & $51.0^{\mathrm{b}} \pm 1.13$ & $+92.4 \%$ & $41.9^{\mathrm{b}} \pm 2.52$ & $+23.9 \%$
\end{tabular}

*Ta37-p is the control strain obtained from Ta37 transformed with a plasmid without insert.

$n=3$, Mann-Whitney U test.

$\mathrm{a}, \mathrm{b}$ For each time point values followed by different superscript letters are significantly different $(p<0.05)$.

\section{Table 3}

Quantification of ergosterol and squalene production by Ta37 and Ta $\Delta$ Tri5 strains in samples from 24 and $96 \mathrm{~h}$ cultures in PDB. \% Variation of produced ergosterol and squalene between the wild-type and mutant are given.

\begin{tabular}{clllll}
\hline & & $\begin{array}{l}\text { Squalene } \\
(\mathrm{mgS} / \mathrm{g} \text { DW })\end{array}$ & $\begin{array}{l}\% \\
\text { Variation }\end{array}$ & $\begin{array}{l}\text { Ergosterol } \\
(\mathrm{mgE} / \mathrm{g} \mathrm{DW})\end{array}$ & $\begin{array}{l}\% \\
\text { Variation }\end{array}$ \\
\hline \multirow{2}{*}{$24 \mathrm{~h}$} & Ta37 & $0.200^{\mathrm{b}} \pm 0.002$ & & $1.065^{\mathrm{b}} \pm 0.045$ & \\
& Ta $\Delta$ Tri5 & $0.377^{\mathrm{a}} \pm 0.052$ & $+88.5 \%$ & $1.975^{\mathrm{a}} \pm 0.085$ & $+85.44 \%$ \\
\multirow{2}{*}{$96 \mathrm{~h}$} & Ta37 & $0.308^{\mathrm{a}} \pm 0.046$ & & $1.705^{\mathrm{b}} \pm 0.175$ & \\
& Ta $\Delta$ Tri5 & $0.385^{\mathrm{a}} \pm 0.034$ & - & $2.870^{\mathrm{a}} \pm 0.260$ & $+68.32 \%$
\end{tabular}

$n=4$, ANOVA.

a,bFor each time point, values followed by different superscript letters are significantly different $(p<0.05)$.

\section{Table 4}

Chitinase activity against $p$-NP- $\beta$-D-glucosaminide (nmol/min/mg DW) measured at four times in culture broths of Ta37-p* and Ta $\Delta$ Tri5 strains.

\begin{tabular}{lllll}
\hline & $24 \mathrm{~h}$ & $48 \mathrm{~h}$ & $72 \mathrm{~h}$ & $96 \mathrm{~h}$ \\
\hline Ta37-p* & $0.05^{\mathrm{a}} \pm 0.0$ & $0.84^{\mathrm{a}} \pm 0.07$ & $2.17^{\mathrm{a}} \pm 0.06$ & $4.65^{\mathrm{a}} \pm 0.96$ \\
Ta $\Delta$ Tri5 & $0.06^{\mathrm{b}} \pm 0.0$ & $0.18^{\mathrm{b}} \pm 0.03$ & $1.79^{\mathrm{b}} \pm 0.14$ & $4.24^{\mathrm{a}} \pm 0.07$ \\
\hline
\end{tabular}

Ta37-p* is a control strain obtained from Ta37 transformed with a plasmid without insert.

${ }^{\mathrm{a}, \mathrm{b}}$ For each time point, values followed by different letters are significantly different (Mann-Whitney U test).

any of the collateral products detected in the tri4-disrupted mutant of $T$. arundinaceum (Malmierca et al., 2012). In addition, all the tri genes located in the "main cluster" of genes involved in HA biosynthesis, with the exception of the tri4 gene, were expressed at a higher level than in the wild type strain. Even though tri5 was disrupted, expression of the partial gene was increased in the mutant. This is an interesting difference in comparison to the tri4-disrupted transformant (Malmierca et al., 2012), which had reduced expression of the tri4 and tri5 genes, presumably as a response to the lack of an efficient processing of trichodiene, the product of the Tri5 protein, which must act as a negative feedback regulator of tri5 expression. The absence of induction of the tri4 gene in the $\mathrm{Ta} \Delta \mathrm{Tri} 5$ strain can be explained by the lack of production of trichodiene, the substrate of Tri4. This suggests that in Trichoderma,
Table 5a

Percentages of radial growth inhibition (RI) of Botrytis cinerea and Rhizoctonia solani by $T$. arundinaceum Ta37 and Ta $\Delta$ Tri5, grown on cellophane or dialysis (cut-off $10 \mathrm{kDa}$ ) membranes.

\begin{tabular}{llllll}
\hline & \multicolumn{2}{l}{ B. cinerea $(72 \mathrm{~h})$} & & \multicolumn{2}{l}{ R. solani $(96 \mathrm{~h})$} \\
\cline { 2 - 3 } \cline { 5 - 6 } & Cellophane & Dialysis & & Cellophane & Dialysis \\
\hline Ta37 & $100.0^{\mathrm{a}} \pm 0.0$ & $88.8^{\mathrm{a}} \pm 0.3$ & & $100.0^{\mathrm{a}} \pm 0.0$ & $100.0^{\mathrm{a}} \pm 0.0$ \\
Ta $\Delta$ Tri5 & $73.5^{\mathrm{b}} \pm 1.0$ & $46.4^{\mathrm{b}} \pm 1.2$ & & $95.2^{\mathrm{b}} \pm 2.1$ & $67.7^{\mathrm{b}} \pm 5.1$ \\
\hline
\end{tabular}

a,b For each column, values followed by different superscript letters are significantly different $(p<0.001)$.

Table 5b

\% RI in HA plates ${ }^{\mathrm{a}}$ when compared with RI in control plates.

\begin{tabular}{llll}
\hline & Control & Ta37 & Ta $\Delta$ Tri5 \\
\hline Cellophane & $+51.74 \pm 3.16$ & $0.00 \pm 0.00$ & $+52.15 \pm 0.83$ \\
Dialysis & $+59.61 \pm 1.01$ & $0.00 \pm 0.00$ & $+73.64 \pm 0.89$
\end{tabular}

Control $=$ diameter of growth of the strain on plates without added HA. Problem $=$ diameter of growth of the strain on plates with added HA.

a $\% \mathrm{RI}$ in HA plates $=100 \times[($ Control-Problem $) /$ Control $]$.

only tri4 is induced by its enzymatic substrate, and that the remaining tri genes are under separate controls, perhaps by Tri6 and/or Tri10, as seen in Fusarium (Tag et al., 2001; Peplow et al., 2003; Seong et al., 2009).

The expression of genes involved in other key steps of the terpene biosynthetic pathway was deeply altered in the tri5disrupted mutant. Thus, it was observed that at $24 \mathrm{~h}$ of growth, the level of expression of $h m g R, d p p 1$, and erg9 genes was significantly increased in comparison with the wild type strain. In parallel, at this time of culture, HMGR activity was strongly increased in the Ta $\Delta$ Tri5 mutant and the production of squalene and ergosterol were increased by $85 \%$ and $88 \%$ respectively. These results can be understood as a response of the cell to prevent the toxic accumulation of isoprenoid pyrophosphates, such as FPP, by redirecting it toward the production of farnesol and squalene/ergosterol (Fig. 8). The expression of erg1 and erg7 genes was not significantly affected in $24 \mathrm{~h}$ cultures, even when the level of ergosterol production was much higher than in the wild type strain, which might indicate that the level of expression of these two genes is not a bottleneck in ergosterol biosynthesis. However, as it has been previously described for Saccharomyces cerevisiae, the squalene epoxidase protein, encoded by the ERG1 gene, would have a more important role as a flux controlling step in the ergosterol biosynthetic pathway (Veen et al., 2003), since this enzyme has a higher $\mathrm{km}$ value for its substrate and lower specific activity than the squalene synthase (encoded by the ERG9 gene) and this could lead to an accumulation of squalene if the flux through the pathway exceeds a certain limit (Asadollahi et al., 2010).
R.s. (control)

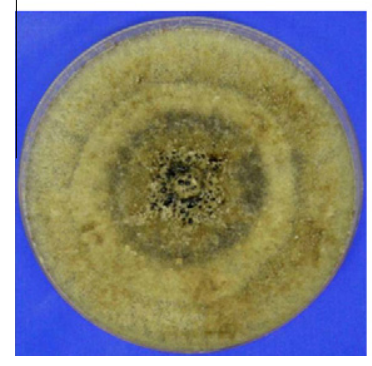

R.s. + Ta37

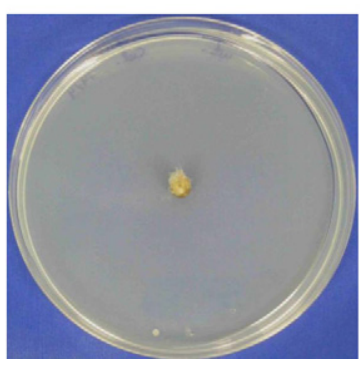

R.s. $+\mathrm{Ta} \Delta \mathrm{Tri5}$

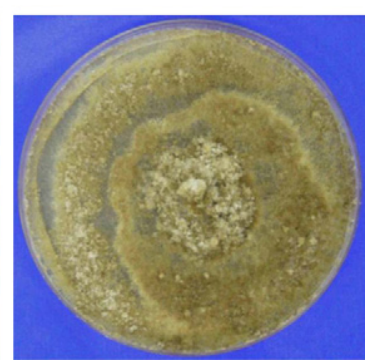

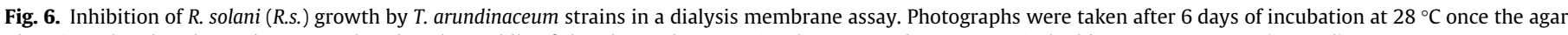
plugs inoculated with $R$. solani were placed in the middle of the plate, where previously a $T$. arundinaceum strain had been grown or not (control). 


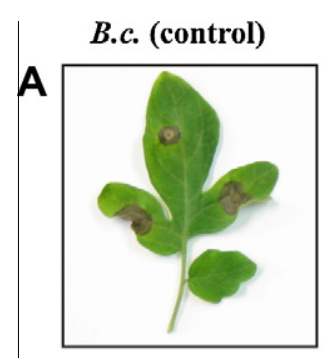

\section{B.c. + Ta37}

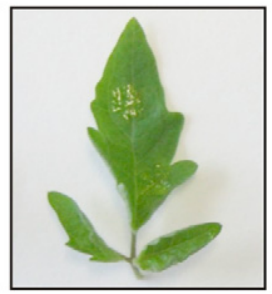

B

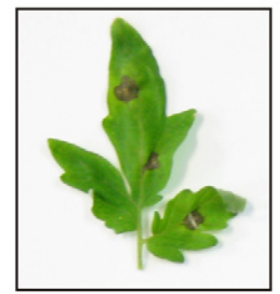

C

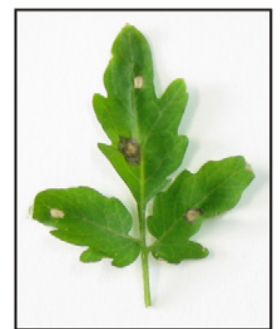

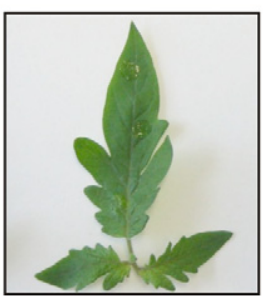

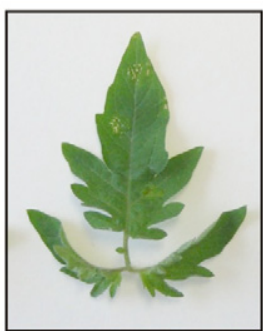

B.c. $+\mathrm{Ta} \Delta \mathrm{Tri5}$
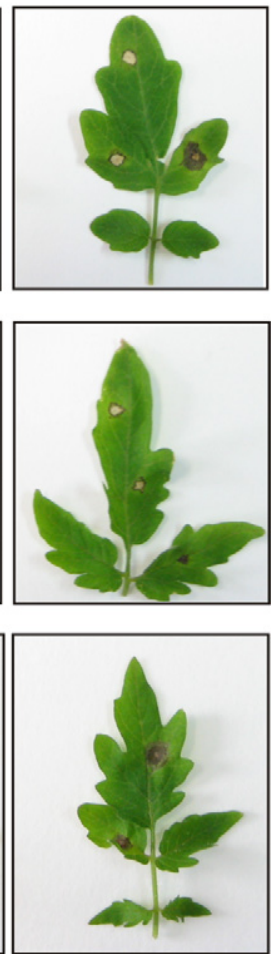

Fig. 7. Pathogenicity assays of $B$. cinerea on tomato leaves from three varieties (A) "Marmande" (B) "Tres Cantos" and (C) "Muchamiel". Leaves were inoculated with B. cinerea spores alone (B.c.) or in combination with broths from strains Ta37 or $\mathrm{Ta} \Delta \mathrm{Tri} 5$. The experiment was performed on 12 leaves, incubated until $96 \mathrm{~h}$, and repeated 3 times.

\section{Table 6}

Size of the $B$. cinerea lesions (in $\mathrm{mm}$ ) on leaves from three tomato varieties measured at two different times after pathogen inoculation without (control) or with culture broth of the different $T$. arundinaceum strains used in this work. Data were analyzed by ANOVA (Analysis of variance) and the significant differences were determined by a Duncan Test with a $p<0.05$ using the IBM SPSS Statistics 19 software.

\begin{tabular}{|c|c|c|c|}
\hline & Control & Ta37 & Ta $\Delta$ Tri5 \\
\hline \multicolumn{4}{|c|}{ Tomato var. Marmande $(n=71)$ : } \\
\hline $48 \mathrm{~h}$ & $5.13^{\mathrm{a}} \pm 1.31$ & $0.99^{\mathrm{C}} \pm 1.38$ & $1.46^{\mathrm{b}} \pm 1.14$ \\
\hline $72 \mathrm{~h}$ & $6.96^{\mathrm{a}} \pm 2.02$ & $1.16^{\mathrm{c}} \pm 1.55$ & $2.72^{\mathrm{b}} \pm 1.86$ \\
\hline \multicolumn{4}{|c|}{ Tomato var. Tres cantos $(n=71)$ : } \\
\hline $48 \mathrm{~h}$ & $4.58^{\mathrm{a}} \pm 0.93$ & $0.04^{\mathrm{c}} \pm 0.20$ & $1.38^{\mathrm{b}} \pm 1.19$ \\
\hline $72 \mathrm{~h}$ & $6.46^{\mathrm{a}} \pm 1.73$ & $0.29^{c} \pm 0.69$ & $2.71^{\mathrm{b}} \pm 1.71$ \\
\hline \multicolumn{4}{|c|}{ Tomato var. Muchamiel $(n=71)$ : } \\
\hline $48 \mathrm{~h}$ & $4.76^{\mathrm{a}} \pm 1.13$ & $0.28^{\mathrm{c}} \pm 0.56$ & $1.49^{\mathrm{b}} \pm 1.12$ \\
\hline $72 \mathrm{~h}$ & $6.54^{\mathrm{a}} \pm 2.15$ & $0.58^{\mathrm{C}} \pm 1.02$ & $3.07^{b} \pm 2.02$ \\
\hline
\end{tabular}

a,b,c For each tomato variety and each time point, values followed by different superscript letters are significantly different.

At $96 \mathrm{~h}$, the level of squalene in cultures of the tri5-disrupted mutant was similar to that in the Ta37 strain, but the ergosterol level in the mutant was elevated, even though the difference with the wild type strain was less than that observed at $24 \mathrm{~h}$. This would indicate that at this time point the accumulated squalene has been efficiently processed to ergosterol. The levels of $h m g R, d p p 1$, and erg9 gene expression and the level of HMGR activity were reduced in comparison with those detected at $24 \mathrm{~h}$, probably as a result of the non-accumulation of squalene and/or FPP. The expression of erg1 and erg7 genes was also repressed in comparison with the wild type strain, even when the level of ergosterol was higher in the tri5disrupted mutant, which led us to hypothesize that the expression of these two genes is not limiting for ergosterol biosynthesis at any of the assayed times. These results correlate well with a similar effect described in S. cerevisiae, where the attenuation in the expression of the squalene synthase encoding gene (ERG9 gene) stimulated sesquiterpene production as a result of a redirection of the FPP pool (Paradise et al., 2008; Asadollahi et al., 2010).

The regulation of the mevalonate pathway in eukaryotes is complex, but HMGR and the FPP branch point represent two key regulation steps (Maury et al., 2005). The HMGR enzyme has been studied mainly in mammals, where it has been recently described that its endoplasmic reticulum associated degradation (ERAD) is regulated by a nonsterol signal, in the form of the geranylgeranyl moiety of a protein, and a sterologenic signal in the form of squalene (Leichner et al., 2011). In filamentous fungi, it is not known yet if HMGR enzyme degradation is regulated in a similar way. However, the increases in HMGR activity and in ergosterol level observed in the present work at 24 and $96 \mathrm{~h}$ of growth can be additionally explained as a way to avoid the accumulation of squalene, which might indicate the existence of a mechanism that regulates HMGR degradation by a similar way to that observed in mammals (Fig. 8). Nevertheless, additional studies would be needed to confirm this hypothesis.

In the present work we have found, as indicated above, that in $96 \mathrm{~h}$ old mycelia the HMGR activity was higher in the Ta $\Delta$ Tri5 mutant $(+23.9 \%)$ than in the Ta37 strain, even though the level of $h m g R$ gene expression was lower $(0.296, p=0.000)$ in the tri5mutated strain. This lack of correlation between the level of gene expression and the activity of its corresponding enzyme activity might be explained not only by the regulation of HMGR stability discussed above, but by other phenomena as well, such as stability of the mRNAs, ribosome occupancy, and protein abundance and stability (Maier et al., 2009).

The differences in the chitinase activity observed in the Ta $\Delta$ Tri5 strain, which showed similar or slightly lower activity level as in $\mathrm{Ta} 37$, in comparison with the Ta $\Delta$ Tri4 mutant which had increased activity, can perhaps be explained by the fact that even though these mutants are affected in the same biosynthetic pathway, they show important differences. The tri4 disrupted mutant produced, as collateral products, 12,13-epoxytrichoene-2-ol derivatives of trichodiene that may have some regulatory function on the induction of chitinase gene expression. These compounds, or other trichothecene intermediates, are not produced by the Ta $\Delta$ Tri5 strain, and therefore would not show any stimulatory effect on chitinase activity.

The antifungal activity of Ta37 and Ta $\Delta$ Tri5 against the two phytopathogenic fungi used in this study was notably different between the two strains, with Ta $\Delta$ Tri5, which lacks HA, causing less inhibition of $B$. cinerea growth than Ta37. If HA was entirely responsible for the observed growth inhibition by Ta37, no inhibition would be expected with the Ta $\Delta$ Tri5/cellophane conditions. Instead, a $73.5 \%$ inhibition was seen. This suggests that HA inhibits the growth of $B$. cinerea by $26.5 \%$ and other metabolites and/or enzymes are responsible for $73.5 \%$ of the observed inhibition, of which $11.2 \%$ [(100-88.8\%) Table 5a] might be due to a higher MW metabolite or enzyme. These calculations suggest that Ta $\Delta \mathrm{Tri} 5$ on dialysis membrane should exhibit an inhibition of $62.3 \%$ (88.8-26.5\%). Instead, we have seen a lower inhibition of $46.4 \%$. Perhaps the higher inhibition on dialysis membranes with the wild type strain is due to a synergistic interaction of HA with other metabolites.

Results on $R$. solani showed that HA contributes only about a 5\% inhibition [(100-95.2\%) see Table 5a] when using the cellophane assay. On dialysis membranes, the inhibition was $67.7 \%$ when $\mathrm{Ta} \Delta$ Tri5 strain was used, again suggesting that HA may interact synergistically with other metabolites to inhibit $R$. solani growth.

It is also possible that in this assay the difference between these two strains might also be due to the lack of production of some kind of compound other than HA in the Ta $\Delta$ Tri5 mutant, although this compound needs to be discovered. The reduction in the bio- 


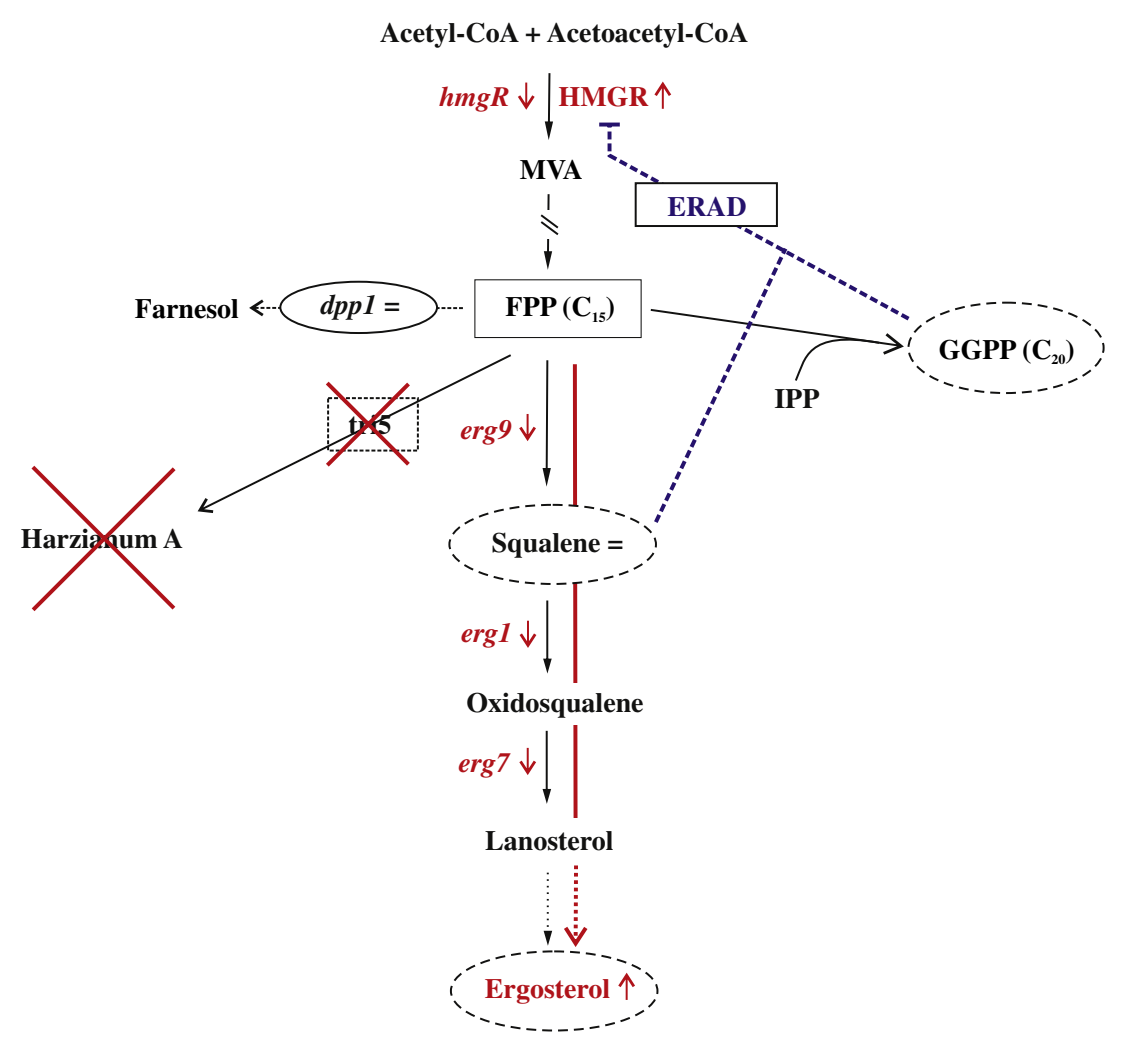

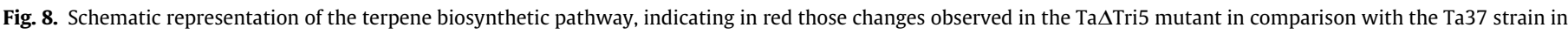

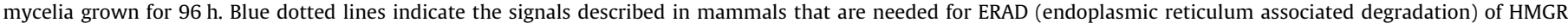
enzyme and that are overcome by the Ta $\Delta$ Tri5 mutant (Leichner et al., 2011). IPP: isopentenyl diphosphate, GGPP: geranylgeranyl diphosphate.

control activity in Ta $\Delta$ Tri5 vs. Ta37 was also confirmed by the reduction in the ability to inhibit the germination of $B$. cinerea conidia, with broths of Ta37 having greater inhibition than those of the tri5-disrupted mutant.

The observed reduction in the biocontrol activity on membrane assays by the tri5 gene disrupted mutant was greater than that detected with a tri4-disrupted mutant (Malmierca et al., 2012). This may be due to the total loss of HA in the Ta $\Delta$ Tri5 mutant, as well as the production of several intermediates in the biosynthesis of trichothecenes and collateral compounds in the tri4-disrupted transformant. These compounds, together with the higher level of chitinase production, could contribute to the greater biocontrol activity shown by the tri4-disrupted mutant in comparison with the tri5-disrupted transformant analyzed in the present work.

The lesions observed in tomato leaves infected with $B$. cinerea conidia and separately treated with culture broths from the two Trichoderma strains used in this work indicate that although HA is an important factor that limits the development of $B$. cinerea disease, other compound/s produced by Trichoderma must be involved as well. This is supported by the results using the broth of Ta $\Delta \operatorname{Tri} 5$ whereby there was a reduction in the size of $B$. cinerea lesions on the tomato leaves. If HA was acting alone, the lesions should have been the same size in both the Ta $\Delta$ Tris and control treatments. This is also supported by biocontrol assays on membranes which showed that in addition to HA, T. arundinaceum produced other compound/s, not yet identified, that may synergistically contribute to the antifungal activity of this metabolite.

\section{Conclusions}

Trichothecene biosynthesis plays an important role in fungal physiology. In general, these compounds show toxicity to plants as well as to animals. This study has shown that Harzianum A, produced by $T$. arundinaceum, is toxic to some phytopathogenic fungi and plays a role in antifungal activity. The presence of HA also contributes to the regulation of intracellular levels of FPP, as well as the levels of intermediates involved in terpene biosynthesis and end products such as ergosterol. The production of trichothecenes by selected fungi is obviously important to their success in their external environment as well as providing for a delicate balance in their internal environment.

\section{Acknowledgments}

Research project funding was from Junta de Castilla y León (GR67 and LE125A12-2) and the Spanish Ministry of Science and Innovation (AGL2006-05660, AGL2009-13431-C01 and AGL200913431-C02). M. Gómez was granted a FPU fellowship by the Spanish Ministry of Science and Innovation (AP2007-02835).

We thank Ulf Thrane for providing the strain $T$. arundinaceum IBT 40837 and J. Álvarez from the University of León and J. Teresi from the Bacterial Foodborne Pathogens and Mycology Unit, USDA/ARS, for their excellent technical assistance.

\section{Appendix A. Supplementary material}

Supplementary data associated with this article can be found, in the online version, at http://dx.doi.org/10.1016/j.fgb.2013.02.001.

\section{References}

Asadollahi, M.A., Maury, J., Schalk, M., Clark, A., Nielsen, J., 2010. Enhancement of farnesyl diphosphate pool as direct precursor of sesquiterpenes through metabolic engineering of the mevalonate pathway in Saccharomyces cerevisiae. Biotechnol. Bioeng. 106, 86-96.

Ausubel, F.M., Brent, R., Kingston, R.E., Moore, D., Smith, J.A., Seidman, J.G., Struhl, K. 1987. Current Protocols in Molecular Biology. John Wiley \& Sons, Inc., New York 
Bradford, M.M., 1976. A rapid and sensitive method for the quantification of microgram quantities of protein utilizing the principle of protein dye binding. Anal. Biochem. 72, 248-254.

Cardoza, R.E., Vizcaíno, J.A., Hermosa, M.R., Monte, E., Gutiérrez, S., 2006a. A comparison of the phenotypic and genetic stability of recombinant Trichoderma spp. generated by protoplast- and Agrobacterium-mediated transformation. J. Microbiol. 44, 383-395.

Cardoza, R.E., Vizcaíno, J.A., Hermosa, M.R., Sousa, S., González, F.J., Llobell, A., Monte, E., Gutiérrez, S., 2006b. Cloning and characterization of the erg1 gene of Trichoderma harzianum: effect of the erg1 silencing on ergosterol biosynthesis and resistance to terbinafine. Fungal Genet. Biol. 43, 164-178.

Cardoza, R.E., Hermosa, M.R., Vizcaíno, J.A., González, F., Llobell, A., Monte, E., Gutiérrez, S., 2007. Partial silencing of a hydroxy-methylglutaryl-CoA reductase encoding gene in Trichoderma harzianum CECT 2413 results in a lower level of resistance to lovastatin and a lower antifungal activity. Fungal Genet. Biol. 44, 269-283.

Cardoza, R.E., Malmierca, M.G., Hermosa, M.R., Alexander, N.J., McCormick, S.P., Proctor, R.H., Tijerino, A.M., Rumbero, A., Monte, E., Gutiérrez, S., 2011 Identification of loci and functional characterization of trichothecene biosynthetic genes in the filamentous fungus Trichoderma. Appl. Environ. Microbiol. 77, 4867-4877.

Corey, E.J., Seiichi, P., Matsuda, T., Bartel, B., 1994. Molecular cloning, characterization, and overexpression of ERG7, the Saccharomyces cerevisiae gene encoding lanosterol synthase. Proc. Natl. Acad. Sci. USA 91, 2211-2215.

Desjardins, A.E., 2006. Fusarium Mycotoxins. Chemistry, Genetics and Biology. St Paul, MN, The American Phytopathological Society.

Faulkner, A., Chen, X., Rush, J., Horazdovsky, B., Waechter, C.J., Carman, G.M. Sternweis, P.C., 1999. The LPP1 and DPP1 gene products account for most of the isoprenoid phosphate phosphatase activities in Saccharomyces cerevisiae. J. Biol. Chem. 274, 14831-14837.

Ghimire, G.P., Lee, H.C., Sohng, J.K., 2009. Improved squalene production via modulation of the methylerythritol 4-phosphate pathway and heterologous expression of genes from Streptomyces peucetius ATCC 27952 in Escherichia coli. Appl. Environ. Microbiol. 75, 7291-7293.

Goldstein, J.L., Brown, M.S., 1990. Regulation of the mevalonate pathway. Nature 343, 425-430.

Harman, G.E., Petzoldt, R., Comis, A., Chen, J., 2004. Interactions between Trichoderma harzianum strain T22 and maize inbred line Mo17 and effects of these interactions on diseases caused by Pythium ultimum and Colletotrichum graminicola. Phytopathology 94, 147-153.

Hermosa, R., Viterbo, A., Chet, I., Monte, E., 2012. Plant-beneficial effects of Trichoderma and of its genes. Microbiology 158, 17-25.

Hohn, T.M., Desjardins, A.E., 1992. Isolation and gene disruption of the Tox 5 gene encoding trichodiene synthase in Gibberella pulicaris. Mol. Plant-Microbe Interactions 5, 249-256.

Hohn, T.M., Van Middlesworth, F., 1986. Purification and characterization of the sesquiterpene cyclase trichodiene synthetase from Fusarium sporotrichioides. Arch. Biochem. Biophys. 251, 756-761.

Leichner, G.S., Avner, R., Harats, D., Roitelman, J., 2011. Metabolically regulated endoplasmic reticulum-associated degradation of 3-Hydroxy-3-methylglutaryl$\mathrm{CoA}$ reductase. Evidence for requirement of a geranylgeranylated protein. J. Biol. Chem. 37, 32150-32161.

Lorito, M., Woo, S.L., Harman, G.E., Monte, E., 2010. Translational research on Trichoderma: from 'omics to the field. Annu. Rev. Phytopathol. 48, 395-417.
Maier, T., Güell, M., Serrano, L., 2009. Correlation of mRNA and protein in complex biological samples. FEBS Lett. 583, 3966-3973.

Malmierca, M.G., Cardoza, R.E., Alexander, N.J., McCormick, S.P., Hermosa, R., Monte, E., Gutiérrez, S., 2012. Involvement of Trichoderma trichothecenes in the biocontrol activity and in the induction of plant defense related genes. Appl. Environ. Microbiol. 78, 4856-4868.

Maury, J., Asadollahi, M.A., Møller, K., Schalk, M., Clark, A., Nielsen, J., 2005. Microbial isoprenoid production: an example of green chemistry through metabolic engineering. Adv. Biochem. Eng. Biotechnol. 100, 19-51.

McCormick, S.P., Stanley, A.M., Stover, N.A., Alexander, N.J., 2011. Trichothecenes: from simple to complex mycotoxins. Toxins (Basel) 3, 802-814.

Meigs, T.E., Simoni, R.D., 1997. Farnesol as a regulator of HMG-CoA reductase degradation: characterization and role of farnesyl pyrophosphatase. Arch. Biochem. Biophys. 345, 1-9.

Paradise, E.M., Kirby, J., Chan, R., Keasling, J.D., 2008. Redirection of flux through the FPP branch-point in Saccharomyces cerevisiae by down-regulating squalene synthase. Biotechnol. Bioeng. 100, 371-378.

Peplow, A.W., Tag, A.G., Garifullina, G.F., Beremand, M.N., 2003. Identification of new genes positively regulated by Tri10 and a regulatory network for trichothecene mycotoxin production. Appl. Environ. Microbiol. 69, 27312736 .

Pfaffl, M.W., Horgan, G.W., Dempfle, L., 2002. Relative expression software tool (REST) for group-wise comparison and statistical analysis of relative expression results in real-time PCR. Nucleic Acids Res. 30, e36.

Punt, P.J., Oliver, R.P., Dingemanse, M.A., Pouwels, P.H., van den Hondel, C.A., 1987. Transformation of Aspergillus based on the hygromycin B resistance marker from Escherichia coli. Gene 56, 117-124.

Seong, K.-Y., Pasquali, M., Zhou, Z., Song, J., Hilburn, K., McCormick, S., Dong, Y., Xu, J.-R., Kistler, H.C., 2009. Global gene regulation by Fusarium transcription factors Tri6 and Tri10 reveals adaptation for toxin biosynthesis. Mol. Microbiol. 72 , 354-367.

Servouse, M., Karst, F., 1986. Regulation of early enzymes of ergosterol biosynthesis in Saccharomyces cerevisiae. Biochem. J. 240, 541-547.

Shoresh, M., Harman, G.E., Mastouri, F., 2010. Induced systemic resistance and plant responses to fungal biocontrol agents. Annu. Rev. Phytopathol. 48, 21-43.

Tag, A.G., Garifullina, G.F., Peplow, A.W., Ake, C., Phillips Jr., T.M., Hohn, T.M., Beremand, M.N., 2001. A novel regulatory gene, Tri10, controls trichothecene toxin production and gene expression. Appl. Environ. Microbiol. 67, 52945302.

Tijerino, A., Cardoza, R.E., Moraga, J., Malmierca, M.G., Vicente, F., Aleu, J., Collado, I.G., Gutiérrez, S., Monte, E., Hermosa, R., 2011. Overexpression of the trichodiene synthase gene tri5 increases trichodermin production and antimicrobial activity in Trichoderma brevicompactum. Fungal Genet. Biol. 48, 285-296.

Turgeon, B.G., Garber, R.C., Yoder, O.C., 1987. Development of a fungal transformation system based on selection of sequences with promoter activity. Mol. Cell Biol. 17, 3297-3305.

Vandesompele, J., De Preter, K., Pattyn, F., Poppe, B., Van Roy, N., De Paepe, A. Speleman, F., 2002. Accurate normalization of real-time quantitative RT-PCR data by geometric averaging of multiple internal control genes. Genome Biol. 3, 0034.1-0034.11.

Veen, M., Stahl, U., Lang, C., 2003. Combined overexpression of genes of the ergosterol biosynthetic pathway leads to accumulation of sterols in Saccharomyces cerevisiae. FEMS Yeast Res. 4, 87-95. 